\title{
Endotracheal intubation and outcome in high-risk patients with acute myocardial infarction undergoing primary angioplasty
}

Francesco Tomassini*, Andrea Gagnor, Nicolò Montali, Alfonso Gambino, Mario Bollati, Vincenzo Infantino and Ferdinando Varbella

*Correspondence: tomascard.tomassini@gmail.com

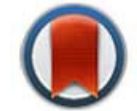

CrossMark

- Click for updates

Department of Cardiology, Infermi Hospital, Rivoli, Italy.

\begin{abstract}
Background: Patients with acute myocardial infarction (AMI) who undergo endotracheal intubation (ETI) are at high risk for mortality, but the outcome of those patients submitted to primary angioplasty (PCI) has not yet clearly reported.

Methods: We collected data about all consecutive patients with AMI within 12 hours who underwent primary PCI and analyzed clinical and procedural characteristics as well as in-hospital mortality of ETI compared to no-ETI patients.

Results: From September 2001 to June 2010, 1251 patients underwent primary PCI and 99 (7.9\%) of them underwent ETI. ETI patients were more likely to be hypertensive ( $76.8 \%$ vs $67.8 \%, \mathrm{p}=0.003)$, diabetic $43.4 \%$ vs $17.9 \%$, $\mathrm{p}<0.0001)$, resuscitated by cardiac arrest $(68.7 \%$ vs $0.7 \%, \mathrm{p}<0.0001)$, to present with cardiogenic shock (CS) $(61.6 \% \%$ vs $8.1 \%, \mathrm{p}<0.0001)$, with a lower left ventricular ejection fraction (LVEF) (38.9 $\pm 9.4 \%$ vs $48.9 \pm 9.2 \%, \mathrm{p}<0.0001)$ and to be treated with intra-aortic balloon counterpulsation (IABP) $(60.1 \%$ vs $15.4 \%, \mathrm{p}<0.0001)$. The in-hospital mortality was higher in ETI patients $(37.4 \%$ vs $4.3 \%, \mathrm{p}<0.0001)$ and they were more likely to undergo stent thrombosis ( $3 \%$ vs $0.34 \%, \mathrm{p}=0.006$ ). After using the propensity score modelling. Considering the risk profile, ETI was associated to higher in hospital mortality in the patients at higher risk ( $39.8 \%$ vs $18.5 \%, \mathrm{p}=0.003)$. Moreover, ETI was one of the most powerful predictors of in-hospital mortality at multivariate analysis (OR 37.04, 95\% CI 6.0-228.45, p=0.0001).

Conclusions: ETI was found to be an independent predictor of mortality in high-risk AMI patients undergoing primary angioplasty. The implications for current clinical care remained undefined.

Keywords: Acute myocardial infarction, endotracheal intubation, primary percutaneous coronary intervention, primary angioplasty
\end{abstract}

\section{Introduction}

Acute myocardial infarction (AMI) represents one of the most frequent causes of lifethreatening diseases. In most industrialized countries, there is a trend toward lower mortality rates from coronary artery disease, achieved, at least in part first by primary prevention [1] and second by the contribution of the coronary care units [2]. Despite considerable medical advances during the last decades in the management of AMI, including the early use of reperfusion strategies with primary angioplasty $(\mathrm{PCl})$ with or without coronary stenting $[3,4]$, the mortality rate remains high in high-risk settings such as cardiac arrest necessitating cardiopulmonary resuscitation, acute pulmonary edema, cardiogenic shock and reduced left ventricular ejection fraction (LVEF) $\leq 0.40$ [5-7]. All these events may increase the severity and the number of failed organs, with a mortality rate reported to be as high as $\geq 60 \%$ [8].

Despite aggressive management, some of these patients require endo-tracheal intubation (ETI) and invasive mechanical ventilation. Nevertheless, little is known about the prognosis of patients admitted for complicated AMI requiring ETI and mechanical ventilation undergoing primary angioplasty. The aim of this retrospective study was to assess the clinical characteristics and the in-hospital mortality of a population of patients with complicated $\mathrm{AMI}$ who underwent primary $\mathrm{PCl}$ requiring $\mathrm{ETI}$ compared to the patients who did not require ETI and to evaluate the risk of ETI itself as independent predictor of mortality.

\section{Methods}

We reviewed the data of all consecutive patients with AMI admitted to our hospital between September 2001 and June 2010 and treated by primary $\mathrm{PCl}$ within 12 hours of symptom onset. Demographic, clinical and procedural data were collected in a dedicated database (Cardioplanet V.3.0.8, Ebit Aet S.p.A., Genoa, Italy). The study protocol was reviewed and approved by the Ethics Committee of our Institution (ASL 103, Piemonte Region, Italy).

AMI was defined as typical chest pain lasting more than 30 minutes associated with $>0.1 \mathrm{mV}$ ST-segment elevation in $\geq 2$ contiguous electrocardiogram (ECG) leads or with new left bundle branch block. Cardiogenic shock was defined as systolic blood pressure $<90 \mathrm{mmHg}$ (without inotropic drugs or intra-aortic balloon pump support) secondary to severe ventricular dysfunction and associated with signs of end-organ hypoperfusion (e.g., cold and diaphoretic extremities, altered mental status, anuria). The diagnosis of acute cardiogenic pulmonary edema was disclosed when patients presented the combination of severe dyspnea on exertion, rales covering

(C) 2014 Tomassini et al; licensee Herbert Publications Ltd. This is an Open Access article distributed under the terms of Creative Commons Attribution License (http://creativecommons.org/licenses/by/3.0). This permits unrestricted use, distribution, and reproduction in any medium, provided the original work is properly cited. 
Tomassini et al. Journal of Anesthesiology \& Clinical Science 2014,

both lung fields, and typical findings on a chest radiograph (diffuse interstitial or alveolar infiltrates).

All AMI patients who complained symptoms for $\leq 12$ hours were immediately transferred to the catheterization laboratory for urgent coronary angiography. The use of abciximab, thrombus aspiration (TA), intra-aortic balloon pump (IABP) support was at the total discretion of the operator. A successful procedure was defined as a residual stenosis of treated vessels $<40 \%$ associated with a Thrombolysis In Myocardial Infarction (TIMI) 3 grade flow [9].

All patients were routinely treated with aspirin $(325 \mathrm{mg}$ upon arrival, and then $100 \mathrm{mg}$ daily), clopidogrel (loading dose of 300 or $600 \mathrm{mg}$, and then $75 \mathrm{mg}$ daily) and with an intravenous bolus of unfractionated heparin $(100 \mathrm{U} / \mathrm{kg}$ body weight, or $60 \mathrm{U} / \mathrm{kg}$ body weight if also abciximab was given). Heparin therapy was stopped after the procedure, but, in case of IABP use, it was continued until its removal. When used, abciximab infusion was continued for 12 hours after the procedure. The patients undergoing ETI received the oral antiplatelet therapy through a nasogastric tube until the withdrawal of mechanical ventilation. All patients underwent an echocardiogram before coronary angiography to assess the LVEF by Simpson's rule [10] and to rule out mechanical complications (i.e., cardiac tamponade, interventricular septum or left ventricular free wall rupture, acute mitral regurgitation due to papillary muscle rupture).

\section{Clinical end-points}

The primary end point of the study was in-hospital death. Furthermore, we evaluated the occurrence of stent thrombosis and of major bleedings. Stent thrombosis was defined as definite and probable according to the Academic Research Consortium [11]; major bleedings were defined according to the Thrombolyis In Myocardial Infarction (TIMI) classification [12].

\section{Statistical analysis}

Data are reported as means (with standard deviations) or proportions. Continuous variables were compared by t-test, whereas categorical variables were compared by chi-square test. Multivariate logistic regression analysis was applied to identify independent predictors of in-hospital mortality. To this scope all variables showing $p$ values $<0.1$ at standard statistical analysis were entered into the multivariate model and included age $\geq 75$ years, female gender, hypertension, diabetes, anterior location of STEMI, cardiac arrest, ETI, cardiogenic shock, LVEF $\leq 40 \%$, total ischemic time (time from symptoms onset to reperfusion with $\mathrm{PCl}$ ), multivessel disease, left main coronary artery disease, pre-PCI TIMI flow $<2$, use of IABP, lack of use of glycoprotein llb-Illa inhibitors, and lack of stent implantation. A $p$ value $<0.05$ was always required for statistical significance. To reduce the impact of treatment selection bias and potential confounding in an observational study, we performed rigorous adjustment for differences in baseline characteristics of patients by the use of weighted Cox proportional hazards regression models with the inverse probability of treatment weighting (IPTW) [13]. The propensity scores were estimated without regard to outcome variables, using multiple logistic regression analysis [14].

Adjusted covariates including patient's age, sex, the presence or absence of a variety of clinical and coexisting conditions, risk factors, clinical diagnosis at the time of $\mathrm{PCl}$, left ventricular function, extent of diseased vessels, infarct localization, renal failure, shock presence, cardiac arrest, TIMI flow, TA, IABP and use of abciximab were used for the generation of propensity scores and five quintiles were identified with increasing risk profile from the first to the fifth.

All model discrimination was assessed with c-statistics, and calibration was assessed with Hosmer-Lemeshow statistics.

With the Greedy $5 \rightarrow 1$ digit match algorithm, we created propensity score-matched pairs without replacement (a 1:1 match) [13-14].

After all of the propensity score matches were performed, we assessed the balance in baseline covariates between the two intervention groups with the paired t test or the Wilcoxon signed rank test for continuous variables, and McNemar's test or the marginal homogeneity test for categorical variables. Comparisons were completed with Cox regression models with robust standard errors that accounted for the clustering of matched pairs. The methods mentioned above were applied to compare the clinical outcomes between the two groups. Analyses were performed using the statistical software SAS System, Version 9.1 (SAS Institute Inc., Cary, NC).

\section{Results}

\section{Characteristics of patients}

From September 2001 to June 2010, 1251 patients were admitted to our catheterization laboratory with a diagnosis of $\mathrm{AMI}$ and underwent primary $\mathrm{PCl}$ at our Centre and form the population of the present study. Patients were divided into two groups according to ETI. One group included 99 patients $(7.9 \%)$ who underwent ETI whereas the other group included 1152 patients (92.1\%) who did not. The clinical characteristics of the two groups are summarized in (Table 1), whereas their angiographic and procedural characteristics are shown in (Table 2). In the ETI group, 68 patients (68.7\%) were intubated for cardiac arrest whereas the remaining 31 patients (31.3\%) required ETI for respiratory failure associated to acute pulmonary edema with or without cardiogenic shock. Moreover, in the same group, 72 patients (72.3\%) underwent ETI before their arrival in the catheterization laboratory. ETI patients were more likely to be hypertensive $(76.8 \%$ vs $67.8 \%$, $p=0.003)$, diabetic $43.4 \%$ vs $17.9 \%, p<0.0001)$, resuscitated by cardiac arrest $(68.7 \%$ vs $0.7 \%, p<0.0001)$, to present with cardiogenic shock (61.6\% \% vs $8.1 \%, \mathrm{p}<0.0001)$, with left main disease $(16.2 \%$ vs $3.8 \%, p<0.0001)$, with a lower LVEF $(38.9 \pm 9.4 \%$ vs $48.9 \pm 9.2 \%, \mathrm{p}<0.0001)$ and to be treated with IABP $(60.1 \%$ vs $15.4 \%, p<0.0001)$ whereas they appeared to 
be less hypercholesterolemic ( $26.3 \%$ vs $37.8 \%$, $\mathrm{p}<0.0001)$. TA and stent implantation were performed less in the ETI group ( $38.4 \%$ vs $54.8 \%, \mathrm{p}<0.0001$ and $80.1 \%$ vs $86.9 \%, \mathrm{p}<0.0001$ respectively).

Table 1. Baseline Clinical Characteristics.

\begin{tabular}{lllll}
\hline & All patients & ETI & No-ETI & p Value \\
\hline Number of patients & 1251 & $99(7.9)$ & $1152(92.1)$ & -- \\
Age & $66 \pm 12$ & $64 \pm 12$ & $65 \pm 12$ & 0.52 \\
$\geq 75$ years & $268(23)$ & $26(26.2)$ & $242(21)$ & 0.52 \\
Females & $314(25.1)$ & $24(24.2)$ & $290(25.2)$ & 0.93 \\
Smoke & $786(62.8)$ & $62(62.3)$ & $724(62.8)$ & 0.3 \\
Hypertension & $857(68.5)$ & $76(76.8)$ & $781(67.8)$ & 0.03 \\
Hypercholesterolemia & $460(36.8)$ & $26(26.3)$ & $434(37.8)$ & $<0.0001$ \\
Diabetes & $250(21.5)$ & $43(43.4)$ & $207(17.9)$ & $<0.0001$ \\
Renal failure* & $42(3.3)$ & $2(2)$ & $40(3.5)$ & 0.6 \\
LVEF (\%) & $48.1 \pm 10$ & $38.9 \pm 9.4$ & $48 \pm 9.3$ & $<0.0001$ \\
LVEF<40\% & $175(15)$ & $45(45.4)$ & $130(11.3)$ & $<0.0001$ \\
Cardiogenic Shock & $155(12.4)$ & $61(61.6)$ & $94(8.1)$ & $<0.0001$ \\
Cardiac arrest & $76(6.1)$ & $68(68.7)$ & $8(0.7)$ & $<0.0001$ \\
Anterior AMI & $577(46.1)$ & $57(57.6)$ & $520(45.1)$ & 0.14 \\
$\begin{array}{l}\text { Total ischemic time } \\
\text { (min) }\end{array}$ & $252 \pm 204$ & $223 \pm 214$ & $255 \pm 203$ & 0.13 \\
\hline
\end{tabular}

Data are $\mathrm{n}(\%)$ or mean \pm SD unless otherwise stated.

${ }^{\star}$ Renal failure defined as baseline creatinine $\geq 2.5 \mathrm{mg} / \mathrm{dec}$ iliter.

gTime from symptoms onset to reperfusion.

Table 2. Angiographic findings and procedural details.

\begin{tabular}{lllll}
\hline & All patients & ETI & No-ETI & p Value \\
\hline Number of patients & 1251 & $99(7.9)$ & $1152(92.1)$ & -- \\
Multivessel disease & $734(58.7)$ & $55(55.5)$ & $666(57.8)$ & 0.16 \\
Left main disease & $60(4.8)$ & $16(16.2)$ & $44(3.8)$ & $<0.0001$ \\
Successful procedure & $1183(94.6)$ & $90(90.1)$ & $1093(94.8)$ & 0.15 \\
IABP & $237(18.9)$ & $60(60.1)$ & $177(15.4)$ & $<0.0001$ \\
GP IIb-IIIa inhibitors & $1051(84)$ & $80(80.1)$ & $962(83.5)$ & 0.58 \\
Thrombus Aspiration & $669(53.5)$ & $38(38.4)$ & $669(54.8)$ & $<0.0001$ \\
Stent implantation & $1081(86.4)$ & $80(80.1)$ & $1001(86.9)$ & $<0.0001$ \\
\hline
\end{tabular}

Data are $\mathrm{n}(\%)$ unless otherwise stated.

* Successful procedure was defined as a residual stenosis of treated vessels $<50 \%$ associated with a Thrombolysis In Myocardial Infarction (TIMI) 3 grade flow.

IABC $=$ Intra-Aortic Balloon Pump.

\section{Clinical events}

In-hospital death of the whole population occurred in 87 patients (6.9\%). The results of the comparisons between ETI and no-ETI patients are shown in (Table 3 ). The rate of inhospital death was significantly higher in the ETI compared to no-ETI group ( $37.4 \%$ vs $4.3 \%, p<0.0001$ ), as the rate of stent thrombosis ( $3 \%$ vs $0.34 \%, p=0.006$ ). The rate of major bleedings did not significantly differ between the two groups ( $3 \%$ in $\mathrm{ETI}$ vs $2.1 \%$ in no-ETI group, $\mathrm{p}=0.79$ ). Multivariate analysis (Table 4) showed that the independent predictors of in-hospital death included age $\geq 75$ years (odds ratio [OR] 3.96, $\mathrm{p}=0.0003), \mathrm{LVEF} \leq 40 \%$ (OR 1.35, $\mathrm{p}=0.02)$, cardiogenic shock (OR 33.4, $\mathrm{p}<0.0001)$, anterior AMI (OR 1.82, 95\% Cl 1.04-3.17, $\mathrm{p}=0.036)$ and $\mathrm{ETI}(\mathrm{OR} 37.04,95 \% \mathrm{Cl} 6.0-228.45, \mathrm{p}=0.0001)$. A total ischemic time $\leq 3$ hours showed a borderline positive impact on survival (OR $0.55, \mathrm{p}=0.05)$, and there was also a non significant tendency of increased mortality in female,

Table 3. In-Hospital Outcomes.

\begin{tabular}{lllll}
\hline & All patients & ETI & No-ETI & p Value \\
\hline Number of patients & 1251 & $99(7.9)$ & $1152(92.1)$ & -- \\
Death & $87(6.9)$ & $37(37.4)$ & $50(4.3)$ & $<0.0001$ \\
Stent Thrombosis & $7(0.56)$ & $3(3)$ & $4(0.34)$ & 0.006 \\
Major Bleedings & $27(2.1)$ & $3(3)$ & $24(2.1)$ & 0.79 \\
\hline
\end{tabular}

Data are $\mathrm{n}(\%)$ unless otherwise stated.

Table 4. Multivariate Analysis of In-Hospital Mortality.

\begin{tabular}{|c|c|c|c|}
\hline & Odds Ratio & $95 \%$ CI & $\mathbf{p}$ \\
\hline Age $\geq 75$ years & 3.96 & $1.89-8.32$ & 0.0003 \\
\hline Male Gender & 0.51 & $0.24-1.07$ & 0.08 \\
\hline Hypertension & 1.31 & $0.71-2.40$ & 0.38 \\
\hline Diabetes & 0.84 & $0.43-1.67$ & 0.62 \\
\hline $\mathrm{LVEF} \leq 40 \%$ & 1.35 & $1.05-1.72$ & 0.02 \\
\hline Cardiac arrest & 0.84 & $0.11-6.11$ & 0.86 \\
\hline Cardiogenic shock & 33.40 & $11.10-100.44$ & $<0.0001$ \\
\hline Endo-tracheal intubation & 37.04 & $6.00-228.45$ & 0.0001 \\
\hline IABP & 1.11 & $0.42-2.99$ & 0.83 \\
\hline Anterior location & 1.82 & $1.04-3.17$ & 0.036 \\
\hline Multivessel disease & 0.87 & $0.49-1.53$ & 0.62 \\
\hline Left main disease & 1.74 & $0.39-7.70$ & 0.46 \\
\hline GP IIb-IIIa inhibitors & 1.14 & $0.50-2.60$ & 0.76 \\
\hline TIMI flow pre-PCI $\geq 2$ & 0.79 & $0.41-1.52$ & 0.48 \\
\hline Thrombus aspiration & 0.67 & $0.36-1.25$ & 0.21 \\
\hline Stent & 0.65 & $0.27-1.57$ & 0.34 \\
\hline Total ischemic time $\leq 3$ hours & 0.55 & $0.30-1.01$ & 0.05 \\
\hline
\end{tabular}

LVEF=Left Ventricular Ejection Fraction

IABP $=$ Intra-aortic Balloon Pump. 
Tomassini et al. Journal of Anesthesiology \& Clinical Science 2014,

compared to male patients ( $O R 0.51, p=0.08$ ). After using the propensity score modelling (Figure 1) ETI was not associated to worse outcomes in the quintiles from the first to the third ( $0.3 \%$ vs $0, p=1$, in the first quintile, $1.6 \%$ vs $0, p=1$ in the second, $2.4 \%$ vs $0, p=1$ in the third) but it was associated to a higher death rate in the fourth and in the fifth quintiles ( $6 \%$ vs $8.7, p=0.04$ and $18.5 \%$ vs $39.8 \%, p=0.003$, respectively).

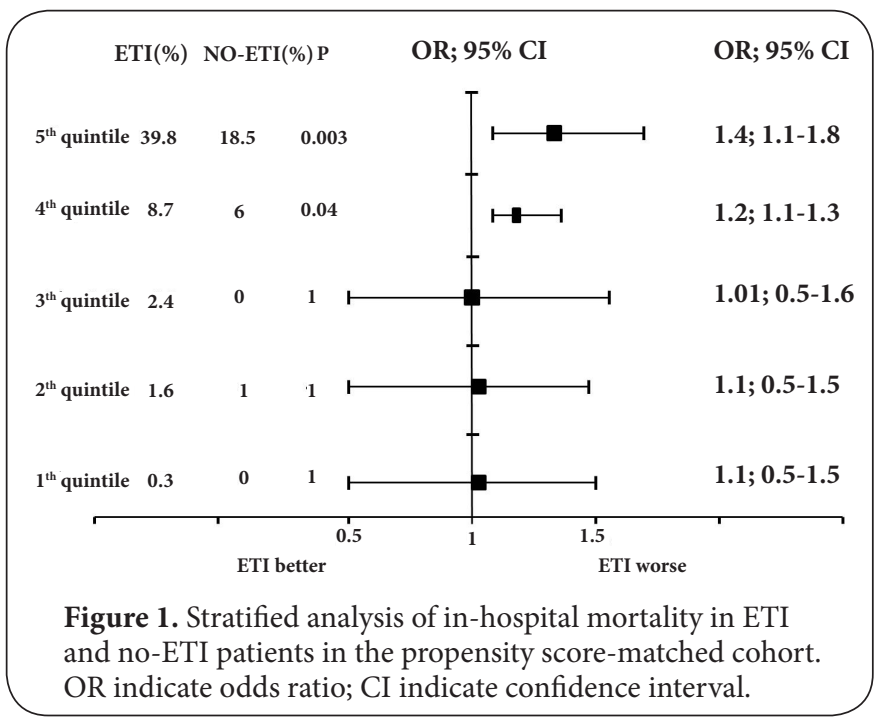

\section{Discussion}

The aim of the present study was to identify the clinical characteristics of the critically ill patients admitted for complicated AMI induced ETI undergoing primary $\mathrm{PCl}$, compared to a similar population of patients not intubated, $\mathrm{ad}$ to assess the role of ETI as a independent risk factor of inhospital mortality. At our knowledge, there are few studies regarding such a population but, unlike our work, they focused on the clinical scores predictive of early mortality [15-17]. Our study confirmed that the in-hospital mortality of ETI patients was significantly higher compared to that of no-ETI patients, but it appeared to be slightly lower than those previous studies in which it ranged between $43 \%$ to $51 \%$. Obviously the ETI patients are more critical in terms of both clinical characteristics and angiographic findings, but the propensity score analysis confirmed the significant negative impact of ETI on in-hospital mortality, at least in very highrisk patients. Furthermore, ETI was one of the most important independent predictors of mortality at multivariate analysis. The reasons of these findings are not completely clear but it could be hypothesized that an important role could be represented by the physiopathological changes induced by ETI itself, including hypotension, iatrogenic hypoxia and bradyarrhythmias [18-22] and by the major complications associated with it, like unrecognized oesophageal intubation, aspiration and pneumothorax $[\mathbf{1 8 , 1 9 , 2 3 ] . ~ I n ~ a ~ s e r i e s ~ o f ~} 1954$ patients received ETI, Wang and coll. found that the rate of one o more errors occurred in 444 (22.7\%) patients, including tube misplacement or dislodgement in 61 (3\%), multiple ETI attempts in 62 (3\%) and failed ETI in 359 (15\%) [24]. Furthermore, other interventions often occur concurrently with ETI like chest compressions, electrical therapy, intravenous access, or the administration of drugs and ETI may influence patient outcome by interacting with or affecting the execution of these simultaneous therapies resulting in unintended hyperventilation, which may be deleterious in certain conditions and may increase the mortality, as shown by Davis and coll [25]. These observations contradict the assumption that aggressive airway intervention is associated with improved resuscitation outcomes [26]. Finally, last but not least, in our study the rate of stent thrombosis was significantly higher in the ETI group. This finding may be due in part to the more critical hemodynamic conditions of these patients that are associated, mainly in cardiogenic shock, with a significant reduction of the absorption of drugs from the intestine [27] in part to the difficulty to give them the needed antiplatelet therapy, mandatory after stent implantation. New intravenous antiplatelet drugs seem promising in reducing thrombotic events related to $\mathrm{PCI}$ [28] and then, if these data are confirmed, they could overcome these issues.

Our study has some important limitations: first, it is a retrospective analysis and is therefore subject to the limitations of such analyses. Due to its retrospective design, a weakness of our study is a deficiency in accurately collecting some history and clinical information like formal neurologic or functional severity scores [29-32] and the number of the patients who receiving mild-induced hypothermia, which has been demonstrated to have a strong beneficial impact on long-term survival and neurological status in the setting of outof-hospital cardiac arrest [33]. Secondly, the nonrandomized nature of the comparison may have resulted into bias: for this reason, propensity score matching further enhanced the comparability of the patients. Third, the data are derived from a single center, which limits their applicability. However, this is likely to be a representative sample of the population of all-comers complicated AMI induced ETI undergone primary $\mathrm{PCl}$ in the real world. To our knowledge, this is the first study that can allow a significant relationship between ETI and inhospital mortality in this population.

\section{Conclusions}

We identified that high-risk AMI patients with ETI undergoing primary $\mathrm{PCl}$ have significantly worse prognosis. However, we do not believe that the correct clinical interpretation is to avoid it at all. Our results most likely signal the presence of underlying problems with this procedure. Therefore, additional studies are needed to better understand the relationship between ETI and in-hospital mortality in such a population.

\section{List of abbreviations}

AMI: Acute Myocardial Infarction 
PCl: Percutaneous Coronary Intervention

LVEF: Left Ventricular Ejection Fraction

ETI: Endotracheal Intubation

ECG: Electrocardiogram

TA: Thrombus Aspiration

IABP: Intra Aortic Balloon Pump

TIMI:Thrombolysis In Myocardial Infarction

\section{Competing interests}

The authors declare that they have no competing interests.

Authors' contributions

\begin{tabular}{|l|c|c|c|c|c|c|c|}
\hline Authors' contributions & FT & AG & NM & AG & MB & VI & FV \\
\hline Research concept and design & $\checkmark$ & - & - & - & -- & -- & -- \\
\hline Collection and/or assembly of data & -- & $\checkmark$ & $\checkmark$ & $\checkmark$ & -- & $\checkmark$ & -- \\
\hline Data analysis and interpretation & -- & - & - & -- & $\checkmark$ & -- & -- \\
\hline Writing the article & $\checkmark$ & -- & -- & -- & -- & -- & -- \\
\hline Critical revision of the article & -- & -- & -- & -- & -- & -- & $\checkmark$ \\
\hline Final approval of article & -- & -- & -- & -- & -- & -- & $\checkmark$ \\
\hline Statistical analysis & -- & -- & -- & -- & $\checkmark$ & -- & - \\
\hline
\end{tabular}

Acknowledgement

We aknowledge the professional contribution of our nursing and technical staff: Antonio Badalì, Giovanni Bovì, Lello Castaldo, Anna Isabello, Giuliana Podio, Cleopatra Sollai, Teresa Strizzi.

\section{Publication history}

EIC: D. John Doyle, Case Western Reserve University, USA.

Received: 14-Aug-2013 Revised: 10-Oct-2013

Accepted: 09-Dec-2013 Published: 04-Feb-2014

\section{References}

1. Nabel EG and Braunwald E. A tale of coronary artery disease and myocardial infarction. N Eng/ J Med. 2012; 366:54-63. | Article | PubMed

2. Rotstein Z, Mandelzweig L, Lavi B, Eldar M, Gottlieb S and Hod H. Does the coronary care unit improve prognosis of patients with acute myocardial infarction? A thrombolytic era study. Eur Heart J. 1999; 20:813-8. | Article | PubMed

3. Grines CL, Browne KF, Marco J, Rothbaum D, Stone GW, O'Keefe J, Overlie P, Donohue B, Chelliah N, Timmis GC and et al. A comparison of immediate angioplasty with thrombolytic therapy for acute myocardial infarction. The Primary Angioplasty in Myocardial Infarction Study Group. N Engl J Med. 1993; 328:673-9. | Article | PubMed

4. Schomig A, Kastrati A, Dirschinger J, Mehilli J, Schricke U, Pache J, Martinoff S, Neumann FJ and Schwaiger M. Coronary stenting plus platelet glycoprotein IIb/IIla blockade compared with tissue plasminogen activator in acute myocardial infarction. Stent versus Thrombolysis for Occluded Coronary Arteries in Patients with Acute Myocardial Infarction Study Investigators. N Engl J Med. 2000; 343:38591. | Article | PubMed

5. Kuch B, Bolte HD, Hoermann A, Meisinger C and Loewel H. What is the real hospital mortality from acute myocardial infarction? Epidemiological vs clinical view. Eur Heart J. 2002; 23:714-20. | Article | PubMed

6. Risk stratification and survival after myocardial infarction. $N$ Eng/ $J$ Med. 1983; 309:331-6. | Article | PubMed

7. Brezins M, Benari B, Papo V, Cohen A, Bursztein S and Markiewicz W. Left ventricular function in patients with acute myocardial infarction, acute pulmonary edema, and mechanical ventilation: relationship to prognosis. Crit Care Med. 1993; 21:380-5. | Article | PubMed

8. Knaus WA, Draper EA, Wagner DP and Zimmerman JE. Prognosis in acute organ-system failure. Ann Surg. 1985; 202:685-93. | Article | PubMed Abstract | PubMed Full Text

9. The Thrombolysis in Myocardial Infarction (TIMI) trial. Phase I findings. TIMI Study Group. N Engl J Med. 1985; 312:932-6. | Article | PubMed

10. Rogers EW, Feigenbaum $\mathrm{H}$ and Weyman $A E$. Echocardiography for quantitation of cardiac chambers. In Progress in Cardiology, vol 8, Philadelphia, Lea \& Febiger, 1979.

11. Mauri L, Hsieh WH, Massaro JM, Ho KK, D’Agostino R and Cutlip DE. Stent thrombosis in randomized clinical trials of drug-eluting stents. N Engl J Med. 2007; 356:1020-9. | Article | PubMed

12. Cannon CP, Battler A, Brindis RG, Cox JL, Ellis SG, Every NR, Flaherty JT, Harrington RA, Krumholz HM and Simoons ML et al. American College of Cardiology key data elements and definitions for measuring the clinical management and outcomes of patients with acute coronary syndromes. A report of the American College of Cardiology Task Force on Clinical Data Standards (Acute Coronary Syndromes Writing Committee). J Am Coll Cardiol. 2001; 38:2114-30. | Article | PubMed

13. Robins JM, Hernan MA and Brumback B. Marginal structural models and causal inference in epidemiology. Epidemiology. 2000; 11:550-60. Article | PubMed

14. D'Agostino RB, Jr. Propensity score methods for bias reduction in the comparison of a treatment to a non-randomized control group. Stat Med. 1998; 17:2265-81. | Article | PubMed

15. Lesage A, Ramakers M, Daubin C, Verrier V, Beynier D, Charbonneau P and du Cheyron D. Complicated acute myocardial infarction requiring mechanical ventilation in the intensive care unit: prognostic factors of clinical outcome in a series of 157 patients. Crit Care Med. 2004; 32:1005. | Article | PubMed

16. Eran $\mathrm{O}$, Novack $\mathrm{V}$, Gilutz $\mathrm{H}$ and Zahger $\mathrm{D}$. Comparison of thrombolysis in myocardial infarction, Global Registry of Acute Coronary Events, and Acute Physiology and Chronic Health Evaluation II risk scores in patients with acute myocardial infarction who require mechanical ventilation for more than 24 hours. Am J Cardiol. 2011; 107:343-6. | Article | PubMed

17. Kouraki K, Schneider S, Uebis R, Tebbe U, Klein HH, Janssens U, Zahn $\mathrm{R}$, Senges J and Zeymer U. Characteristics and clinical outcome of 458 patients with acute myocardial infarction requiring mechanical ventilation. Results of the BEAT registry of the ALKK-study group. Clin Res Cardiol. 2011; 100:235-9. | Article | PubMed

18. Griesdale DE, Bosma TL, Kurth T, Isac G and Chittock DR. Complications of endotracheal intubation in the critically ill. Intensive Care Med. 2008; 34:1835-42. | Article | PubMed

19. Jaber S, Amraoui J, Lefrant JY, Arich C, Cohendy R, Landreau L, Calvet Y, Capdevila X, Mahamat A and Eledjam JJ. Clinical practice and risk factors for immediate complications of endotracheal intubation in the intensive care unit: a prospective, multiple-center study. Crit Care Med. 2006; 34:2355-61. | Article | PubMed

20. Bowles TM, Freshwater-Turner DA, Janssen DJ and Peden CJ. Out-oftheatre tracheal intubation: prospective multicentre study of clinical practice and adverse events. Br J Anaesth. 2011; 107:687-92. | Article | PubMed

21. Mort TC. Emergency tracheal intubation: complications associated with repeated laryngoscopic attempts. Anesth Analg. 2004; 99:607-13. | Article | PubMed

22. Mort TC. The incidence and risk factors for cardiac arrest during emergency tracheal intubation: a justification for incorporating the ASA Guidelines in the remote location. J Clin Anesth. 2004; 16:508-16. | Article I PubMed

23. Schwartz DE, Matthay MA and Cohen NH. Death and other complications of emergency airway management in critically ill adults. A prospective investigation of $\mathbf{2 9 7}$ tracheal intubations. Anesthesiology. 1995; 82:367-76. | Article | PubMed

24. Wang HE, Cook LJ, Chang CC, Yealy DM and Lave JR. Outcomes after outof-hospital endotracheal intubation errors. Resuscitation. 2009; 80:50-5. | Article | PubMed

25. Davis DP, Dunford JV, Poste JC, Ochs M, Holbrook T, Fortlage D, Size MJ, Kennedy $F$ and Hoyt DB. The impact of hypoxia and hyperventilation on 
Tomassini et al. Journal of Anesthesiology \& Clinical Science 2014, http://www.hoajonline.com/journals/pdf/2049-9752-3-1.pdf

outcome after paramedic rapid sequence intubation of severely headinjured patients. J Trauma. 2004; 57:1-8. | Article | PubMed

26. Lyon RM, Ferris JD, Young DM, McKeown DW, Oglesby AJ and Robertson C. Field intubation of cardiac arrest patients: a dying art? Emerg Med J. 2010; 27:321-3. | Article | PubMed

27. Boucher BA, Wood GC and Swanson JM. Pharmacokinetic changes in critical illness. Crit Care Clin. 2006; 22:255-71. | Article | PubMed

28. Bhatt DL, Lincoff AM, Gibson CM, Stone GW, McNulty S, Montalescot G, Kleiman NS, Goodman SG, White HD and Mahaffey KW et al. Intravenous platelet blockade with cangrelor during PCI. N Engl J Med. 2009; 361:2330-41. | Article | PubMed

29. Hudak AM, Caesar RR, Frol AB, Krueger K, Harper CR, Temkin NR, Dikmen SS, Carlile M, Madden C and Diaz-Arrastia R. Functional outcome scales in traumatic brain injury: a comparison of the Glasgow Outcome Scale (Extended) and the Functional Status Examination. J Neurotrauma. 2005; 22:1319-26. | Article | PubMed

30. Stineman MG, Shea JA, Jette A, Tassoni CJ, Ottenbacher KJ, Fiedler R and Granger CV. The Functional Independence Measure: tests of scaling assumptions, structure, and reliability across 20 diverse impairment categories. Arch Phys Med Rehabil. 1996; 77:1101-8. | Article | PubMed

31. Jones $A E$, Trzeciak $S$ and Kline JA. The Sequential Organ Failure Assessment score for predicting outcome in patients with severe sepsis and evidence of hypoperfusion at the time of emergency department presentation. Crit Care Med. 2009; 37:1649-54. | Article | PubMed Abstract | PubMed Full Text

32. Le Gall JR, Lemeshow $S$ and Saulnier F. A new Simplified Acute Physiology Score (SAPS II) based on a European/North American multicenter study. JAMA. 1993; 270:2957-63. | Article | PubMed

33. Zimmermann S, Flachskampf FA, Schneider R, Dechant K, Alff A, Klinghammer $L$, Rittger $H$ and Achenbach S. Mild therapeutic hypothermia after out-of-hospital cardiac arrest complicating STelevation myocardial infarction: long-term results in clinical practice. Clin Cardiol. 2013; 36:414-21. | Article | PubMed

\section{Citation:}

Tomassini F, Gagnor A, Montali N, Gambino A, Bollati $M$, Infantino V and Varbella F. Endotracheal intubation and outcome in high-risk patients with acute myocardial infarction undergoing primary angioplasty. $J$ Anesthesiol Clin Sci. 2014; 3:1. http://dx.doi.org/10.7243/2049-9752-3-1 